\title{
INTELIGÊNCIA EMOCIONAL COMO FERRAMENTA ESTRATÉGICA NA GESTÃO DAS CORPORAÇÕES
}

\author{
Luzia Corsini Dejavite
}

RESUMO: O avanço da ideia de que a inteligência para se tornar completa, necessita considerar as emoções, ocorreu depois da publicação do livro escrito pelo psicólogo e $\mathrm{PhD}$ Daniel Goleman, em 1995, se tornando, cada vez mais, de grande relevância para o mundo corporativo, onde muitas pessoas almejam conquistar destaque e, consequentemente, sucesso, com isso, muitas empresas já perceberam que somente a capacidade de realizar as atividades laborais não é o suficiente, sem ter o cuidado com as relações e comportamentos humanos, sem levar em conta a influência das emoções nas relações e atitudes, colocando a Inteligência Emocional ou IE, como uma das principais ferramentas na busca pelo progresso profissional e organizacional, se consolidando como grande aliada na obtenção de ganhos de competitividade, possibilitando ambientes de trabalho mais harmoniosos e interativos, aumentando a produtividade e agregando maior valor ao produto final. O presente trabalho visa demonstrar a importância e as vantagens dessa temática no mundo empresarial, através de pesquisa bibliográfica.

Palavras-chave: Inteligência Emocional. Relações Humanas. Organizações. Diferencial Competitivo.

ABSTRACT: The advance of the idea that intelligence, to become complete, needs to consider emotions, occurred after the publication of the book written by psychologist and PhD Daniel Goleman, in 1995, becoming, increasingly, of great relevance to the corporate world, where many people aspire to gain prominence and, consequently, success, with this, many companies have realized that just the ability to perform work activities is not enough, without being careful with human relationships and behavior, without taking into account the influence of emotions in relationships and attitudes, placing Emotional Intelligence or EI as one of the main tools in the search for professional and organizational progress, consolidating itself as a great ally in obtaining competitiveness gains, enabling more harmonious and interactive work environments, increasing the productivity and adding greater value to the final product. The present work aims to demonstrate the importance and advantages of this theme in the business world, through bibliographical research.

Keywords: Emotional intelligence. Human relations. Organizations. Competitive Differentia.

\footnotetext{
I Graduada em Ciências Econômicas, Especialista em Gestão de Negócios e Controladoria, Licenciatura Plena em Administração, Mestranda em Administração pela Must University, Email: ludejaviteı23@gmail.com 


\section{INTRODUÇÃO}

A disseminação sobre a Inteligência Emocional ou IE, ocorreu em 1990, através dos pesquisadores Peter Salovey e John Mayer, no entanto, tornou-se mundialmente conhecida em 1995, com a publicação do livro sobre Inteligência Emocional, escrito pelo psicólogo e $\mathrm{PhD}$ Daniel Goleman, tornando-se um sucesso de vendas. Alcançar uma vaga de trabalho no cenário corporativo, na atualidade, é o sonho de muitos profissionais, porém, a competitividade está cada vez mais acirrada, mesmo estando em pleno século XXl, não há garantia de emprego em âmbito nacional e internacional, decorrente da escassez de oportunidades de trabalho para todos, essa carência é consequência das diversas e profundas modificações ocorridas em um período muito pequeno.

Por muito tempo, o profissional acreditava que seu êxito era medido única e exclusivamente através de sua capacidade intelectual, ou seja, da sua condição de raciocínio lógico, através do Quociente de Inteligência (QI), mensurando a atividade cognitiva de um indivíduo e avaliando o seu nível de inteligência. $O$ atual contexto de negócios vem refletindo nas organizações, que delineadas por um novo modelo estratégico de gestão, tem percebido a necessidade de aumentar o controle e desempenho dos seus processos internos e

externos. Alguns especialistas do comportamento humano, como Gardner (1985) e Goleman (1995), retomaram uma nova discussão a respeito do assunto, trazendo a Inteligência Emocional como a principal responsável pelo sucesso das pessoas no ambiente de trabalho. Por isso, muitos profissionais e organizações perceberam que, além de serem capazes de realizar bem as suas atribuições, é fundamental, também, o zelo nas relações e nos comportamentos humanos, considerando a importância das emoções na assertividade das deliberações. O presente trabalho apresentou conceitos de IE, importância da utilização e de seu desenvolvimento no contexto organizacional, utilizou como metodologia a pesquisa bibliográfica de cunho qualitativo, sendo realizado por meio do referencial teórico abordado na disciplina e selecionado a partir das discussões sobre o contexto.

\section{AS EMPRESAS NO CONTEXTO DAS EMOÇÕES}

Os seres humanos apresentam dois tipos de inteligência, a racional e a emocional, determinando que a performance seja a conclusão da melhor interação dessas inteligências e posterior acréscimo de capacidade intelectual. Portanto, as empresas estão atentas às 
competências emocionais durante seus processos de seleção, ascensões e desenvolvimento de pessoal. Segundo Goleman (200I), a Inteligência Emocional contém cinco competências emocionais e sociais básicas que são classificadas por ele como: autopercepção, autorregulamentação motivação, empatia e competências sociais. No entanto, quem apresenta controle das emoções, elevadas autoestima e autoconfiança, tem condições de detectar diversas respostas para os desafios enfrentados diariamente. Segundo Nelson e Low (20II), aprender e praticar habilidades emocionais preparam o ser humano para direcionar o comportamento impulsivo, passando esse a ser, progressivamente, direcionado e consciente.

É evidente que gerenciar conflitos requer a aplicação da capacidade emocional, já que em uma situação de negociação, o indivíduo manifesta ou não, o equilíbrio entre razão e emoção, onde as duas se completam, pois conhecimento técnico, experiência e visão são importantes, porém, quando aliado à IE, os resultados são muito promissores. Estudos demonstram que a Inteligência Emocional decidirá sobre a capacidade do profissional em compreender a importância do controle emocional e do autoconhecimento, os debates são unânimes ao defender a ideia de que as pessoas possuem as inteligências racional e emocional, indicando que o desempenho seja consequência da melhor convivência entre as duas e, por conseguinte, o aumento da habilidade intelectual. As competências emocionais já se tornaram parte importante das atividades de recrutamento, promoções e desenvolvimento do quadro de colaboradores, ou seja, se não compreendermos os sentimentos dos outros, não saberemos lidar com os nossos. Robbins (2005) afirma que as emoções afetam o desempenho no trabalho, em especial as emoções negativas que podem prejudicar o desempenho do profissional. Para Barros (20II), as emoções conduzem, revelam e influenciam o comportamento humano, estando sempre presentes no ambiente organizacional, onde pessoas passam grande parte de sua vida. A capacidade de gerenciar com proficuidade é uma atribuição essencial para o progresso do gestor, porém, os perfis individuais são decisivos na composição de conhecimentos que irão desenvolver a relação entre todos os envolvidos na negociação e nas tomadas de decisões, destacando-se as empresas que são administradas por líderes atentos às modificações, oportunidades de mercado, motivação dos profissionais, que incentivem um relacionamento positivo com seus stakeholders, ou seja, com uma visão organizacional global, com planejamentos estratégicos, táticos e operacionais que alicercem o alcance dos resultados de maneira eficaz 
Esse tipo de inteligência permite melhor qualidade de vida aos indivíduos, controlando mais eficazmente seus sentimentos, alcançando a satisfação no ambiente de trabalho, se relacionando de maneira positiva e minimizando os conflitos, tornando-se uma ferramenta de grande relevância na conquista de excelentes resultados em uma organização, condicionando os gestores a terem melhor autoconhecimento e domínio sobre si mesmos, desviando dos conflitos e buscando solucionar as dificuldades de forma paciente e estabilizada.

O ambiente corporativo apresenta diversas situações que causam fortes tensões, podendo provocar a perda parcial ou total do controle emocional das pessoas e, com isso, sérios prejuízos podem ocorrer, comprometendo os resultados da companhia. Trata-se, portanto, de um tema de grande valia para as organizações, já que a administração das emoções proporciona ganhos altamente significativos com relação à produtividade das companhias, corroborando com sua capacidade competitiva. O desenvolvimento das competências emocionais dará sustentação à pessoa na adaptação da realidade da empresa e suas relações sociais, adquirindo sucesso no enfrentamento dos problemas impostos pela ocupação, o mundo corporativo onde essas instituições estão inseridas é globalizado, com frequentes e intensas alterações, ocasionando muitas incertezas, volatilidades e pressões, diante desses obstáculos é preciso definir estratégias que evitem danos à produção e ao clima organizacional. Os gestores são cruciais nas empresas, podendo contribuir com o progresso do indivíduo e da organização.

Para Torres (2019), a inteligência emocional auxilia na identificação das emoções, auxiliando assim nas tomadas de decisões, podendo obter maiores sucessos em todos os ramos da vida. A IE vem sendo incentivada e valorizada no mercado corporativo, pois se tornou grande aliada na conquista de ganhos de competitividade dos empreendimentos, possibilitando ambientes laborais mais harmônicos e com melhor engajamento entre as equipes de trabalho, proporcionando aumento da produtividade, resultados mais eficazes e, consequentemente, maior valor agregado ao produto.

O desafio da gestão atual, para fortalecer a lucratividade empresarial, é o gerenciamento de pessoas, apresentando uma estratégia diferenciada de administração, almejando o crescimento do monitoramento e atuação das suas operações internas e externas, onde o colaborador vem ampliando seu espaço dentro das companhias, por demonstrar uma postura estrategista, superando as expectativas da organização e do cliente. 
Considerando que o cenário é altamente concorrido, a empresa necessita criar um ambiente profissional equilibrado e harmônico, onde priorize o atendimento às necessidades dos colaboradores e seu bem-estar. Existem diferentes tipos de comportamentos humanos, cada um tem um jeito de perceber e agir em determinadas situações, esses comportamentos podem ser controlados e influenciados de diversas formas, a fim de atingir os objetivos propostos (França, 20Io). Entretanto, é preciso conhecer o nível de IE dos gestores, para que possam controlar suas emoções e colaborar com um espaço onde as inteligências se complementem, com a finalidade de tornar as decisões mais assertivas e eficazes, garantindo resultados que cooperem na maximização da rentabilidade empresarial. Existem algumas capacidades humanas que auxiliam no alcance da excelência do desempenho na organização, conforme (Johann, 2013):

- Comunicação assertiva: ter clareza e propósito nas colocações;

- Adaptabilidade: aceitar as transformações do mercado de trabalho, compreendendo também as mudanças na empresa;

- Habilidade de negociar: saber trabalhar em equipe, a fim de ter um bom desempenho nas tarefas;

- Desejo de contribuir: ter segurança nas atividades desempenhadas, para contribuir com o grupo e a organização.

\section{DESENVOLVENDO A IE NAS ORGANIZAÇÕES}

Dentre os vários fatores que merecem atenção do mundo empresarial, a criatividade, a cooperação, a troca de informações e facilidade de movimentação aos espaços de convivência entre os membros das equipes, incluindo os líderes e a alta cúpula da administração, pausas durante as tarefas laborais, realização de atividades físicas, meditação, alimentação balanceada, estímulo à motivação, visando a melhoria das competências e habilidades emocionais, pois quando acentuamos os graus de energia e percepção, liberamos a atividade cerebral e as sensações que estimulam uma maior atenção ao ambiente, às pessoas ao nosso redor e, também, aos próprios sentimentos e pensamentos. 
Ao identificarmos as diversas formas de sentir, ordenar as nossas emoções e as dos outros, conseguimos compreender melhor nossos sentimentos, e, consequentemente, colocar em prática na realização do trabalho nas entidades, através, por exemplo, dos conceitos da alquimia mental, onde ocorre a utilização de várias metodologias de modificação de pensamentos negativos em positivos, através da comutação mental, porém, os colaboradores e a liderança tem a responsabilidade de oferecer ambientes onde favoreça a participação de todas as pessoas envolvidas, dando maior ênfase ao processo do que aos investimentos financeiros realizados, pois estes serão consequência do empenho e comprometimento da equipe, não perder uma única sinalização, conhecer as diversas personalidades individuais através do mapeamento comportamental, visando a identificação dos pontos fortes e fracos das pessoas, explorando ao máximo o potencial de cada um, aproximando a capacidade cognitiva dos elementos e seu campo emocional, através da contextualização, percebendo que as competências socioemocionais são imprescindíveis, por meio de treinamentos, como o Team Building, que é usado na solução de problemas ou no fortalecimento do desempenho das equipes, através da realização de atividades descontraídas, visando melhorar os relacionamentos humanos e auxiliar os colaboradores na identificação das facilidades e dificuldades dos companheiros de trabalho, cooperando com seu desenvolvimento pessoal e profissional, capacitações, parceria com empresas de consultorias, cursos e interferências pontuais e individuais, através do coach e mentor. Com isso, precisam estar adaptadas para receber funcionários de diferentes tipos de culturas, e, também, precisam envolver os colaboradores a saber respeitar as distinções que cada indivíduo possui (Silva, Silva e Bergamini, 2018).

Os programas de desenvolvimento profissional devem refletir na melhoria significativa das interações e integrações, na diminuição dos conflitos, ansiedade, rancor, medos, decepções, inseguranças e incertezas, que fazem parte da realidade da vida organizacional. Para que um líder possa atingir a liderança de forma eficiente, o mesmo deve iniciar pela autoconsciência, saber primeiramente quem ele é, e quais são os seus valores.

A agilidade das mudanças políticas, sociais, tecnológicas e econômicas, exigem a aplicação da IE, que é uma competência intrínseca ao ser humano e que pode ser melhorada continuamente, através da prática. Mesmo que as empresas vejam como importante o desenvolvimento emocional, os problemas costumam aparecer quando se inicia a implantação das ações, ainda que a cultura da empresa local concorde, as dificuldades 
poderão estar concentradas nos funcionários, dificultando o acesso às suas emoções, por ainda não possuírem um autoconhecimento adequado, por questões de distúrbios de conduta e aquelas que apresentam forte resistência à mudança na sua maneira de interagir com os outros. As estratégias complementares de análise, como as pesquisas sobre o clima organizacional, feedbacks de avaliações de desempenho e de interesses das equipes com relação ao avanço das atividades realizadas, dão subsídios para diagnosticar os gargalos emocionais e corrobora com a organização e planejamento dos treinamentos e capacitações relacionadas ao desenvolvimento da Inteligência Emocional.

\section{${ }_{4}$ CONSIDERAÇÕES FINAIS}

A Inteligência emocional tem se mostrado como uma ferramenta estratégica na gestão das organizações, pois abrange o próprio controle emocional e dos indivíduos à sua volta, influenciando diretamente nas relações humanas e tomadas de decisões no cenário corporativo, para que possa administrá-la com eficácia, considerando os diversos tipos de personalidades e sentimentos distintos, evitando os conflitos e, consequentemente, prejuízos no desenvolvimento das atividades laborais.

A IE precisa ser ratificada por todos os gestores e profissionais das corporações, como sendo um fator indispensável para o sucesso individual e organizacional, onde os líderes possuem um papel de grande relevância na condução de seus liderados, visando um ambiente harmônico e equilibrado, embasado na confiança e respeito entre todos, já que trata-se de uma condição que pode ser aprendida e aperfeiçoada continuamente, através de treinamentos, cursos e interferências pontuais, como por exemplo, os serviços de coaching, parcerias com consultoras organizacionais, treinamentos, como Alquimia Mental e Team Building, estimulo à criação e inovação, cooperação, trabalho em equipe, maior autonomia e participação nas decisões da empresa, acesso facilitado aos espaços de convivência entre os membros das equipes, incluindo os gestores e a alta administração, momentos de descanso durante as tarefas, realização de atividades físicas, alimentação balanceada, estímulo à motivação, almejando o aperfeiçoamento contínuo dos talentos e capacidades emocionais.

Portanto, verifica-se que a IE é um tema muito importante, que se aplicado adequadamente, pode gerar excelentes resultados para o empreendimento, favorecendo não somente o gestor no desenvolvimento de suas competências socioemocionais, mas, também, a todos os membros que compõem a empresa, aumentando a motivação, a qualidade de vida 
e a produtividade. Comandar empresas, não é somente gerenciar o seu patrimônio, mas também administrar pessoas, podendo ser a função mais desafiadora dentre todas, por isso é essencial o gerenciamento das emoções, desde as mais simples às mais complexas, gerando espaços laborais mais humanizados, com maiores credibilidade e autoestima dos indivíduos, estimulando o envolvimento e comprometimento com os propósitos da organização, com foco no crescimento mútuo.

\section{REFERÊNCIAS BIBLIOGRÁFICAS}

Barros, M. C. Inteligência Emocional, Confiança do Empregado na Organização e BemEstar no Trabalho: Um estudo com Executivos, São Bernardo dos Campos, 20II. Disponível em: Acesso em: 25 maio 2019.

França, A. C. L. Comportamento Organizacional: conceitos e práticas. São Paulo: Saraiva, 2010.

Gardner, H. A Teoria das Inteligências Múltiplas. Rio de Janeiro: Campus, 1985.

Goleman, D. Inteligência Emocional: a teoria revolucionária que redefine o que é ser inteligente. Rio de Janeiro: Objetiva, 1995.

Goleman D. Trabalhando com a Inteligência Emocional. Rio de Janeiro: Objetiva, 200 .

Johann, S. Comportamento Organizacional. São Paulo: Saraiva, 2013.

Nelson, D.; Low, G. Emotional Intelligence. 2. ed. Achieving Academic and Career Excellence. Boston: Pearson Education, 201.

Robbin, S. P. Comportamento Organizacional. São Paulo: Pearson Prenuce Hall, 2005.

Silva, F. D. D.; Silva, E. R. D.; Bergamini, G. B. O Clima Organizacional como Fator Para - Desempenho Profissional. Revista Científica da Faculdade de Educação e Meio Ambiente - FAEMA, Ariquemes, dezembro 2018. Disponível em: Acesso em: 04 maio 2019.

Torres, J. Inteligência Emocional: Por que se preocupar com isso? BLOG BB PREVIDÊNCIA, 2019. Disponível em: Acesso em: I9 maio 2019 